\title{
LA PARTICIPACIÓN MALAGUEÑA EN LA CONQUISTA DE LA FLORIDA: DE LA FUNDACIÓN DE SAN AGUSTÍN A LA EXPLORACIÓN DE CAROLINA DEL NORTE (1565-1570)
}

\author{
David Cuevas Góngora \\ UNIVERSIDAD DE MÁLAGA
}

\begin{abstract}
RESUMEN
En 2015 se cumplía el $450^{\circ}$ aniversario de la fundación de San Agustín de la Florida por los españoles de don Pedro Menéndez de Avilés, considerada la ciudad más antigua de EE.UU. El presente estudio pretende rescatar de la memoria a los malagueños que participaron tanto en la fundación de San Agustín como en los acontecimientos posteriores por el territorio hasta alcanzar las latitudes de Carolina del Norte y Virginia; en un empeño del imperio de Felipe II por expulsar a las potencias extranjeras de la zona, controlar el territorio y mantener la seguridad de las flotas del oro y plata americanos ante la piratería.
\end{abstract}

\begin{abstract}
In 2015 will celebrate the $450^{\text {th }}$ anniversary of foundation of St. Augustine of Florida by spanish of Adelantado don Pedro Menéndez de Avilés, this city is considerate the most ancient of EE.UU. This report pretends to rescue the participation of habitants from Málaga both the founding St. Augustine as in the subsequent events in the territory reaching latitudes of North Caroline and Virginia; in a effort empire of Philip II to expel foreign powers in the area, control the territory and to keep the security of gold and silver fleets americans against piracy.
\end{abstract}

PALABRAS CLAVE: Málaga, fundación, San Agustín de la Florida, exploración, conquista, siglo XVI

KEYWORDS: Málaga, foundation, St. Augustine of Florida, exploration, conquest, 16th century 


\section{INTRODUCCIÓN}

Este artículo entra dentro de los estudios históricos de carácter prosopográfico, cuyas directrices nos permiten la posibilidad de construir un grupo, definir las personas objetos de estudio, establecer límites espacio-temporales en cuanto a cronología, geografía, temática, formular hipótesis de trabajo y cuestiones históricas a tratar. Así como la inclusión de datos para la realización de biografías.

Teniendo todo esto en cuenta, se ha querido enfocar el presente trabajo sobre un aspecto poco tratado en la historiografía malagueña ${ }^{1}$. La constatación del aporte malacitano en las empresas de descubrimiento, conquista y colonización del Nuevo Mundo o América, y en este caso concreto, a la región de la Florida, al cumplirse en 2015 el $450^{\circ}$ aniversario de la fundación de San Agustín de la Florida, considerada la ciudad de fundación europea más antigua de Norteamérica.

Así pues, el presente estudio entra dentro de aquellos que indagan en la composición de las huestes y del colectivo de conquistadores-pobladores menos conocidos, pues como muy bien señalan Carmen Gómez Pérez y Juan Marchena Fernández en su obra sobre diversas huestes:

...porque, mientras es posible conocer, hasta sus más mínimos detalles, la vida, hechos y hazañas

de los grandes adalides, de los más afamados capitanes, incluso de los canallas de la conquista..., en cambio, sobre el piquero, el arcabucero, la gran masa que arrostraba las dificultades del camino y de la empresa, los que posibilitaban hacer realidad el sueño de oro y gloria del capitán, sobre ellos, bien poco podemos $\operatorname{decir...2}$

Trabajo que según los mismos autores es complicado pero necesario: "la búsqueda del anónimo es pues la tarea más difícil pero también la más necesaria"3. Un tipo de investigación que ha dado lugar a grandes trabajos del

1. Existen escasos trabajos referidos a esta parte de la Historia de Málaga. Entre ellos están: Ma . S. Santos Arrebola (1999), 23-30. Ma I. Pérez De Colosía RodríGuez (1999), 7-22 y E. Anguita Galán y J. Moreno Gómez (1992), aunque este último trabajo sólo recoge una serie de biografías de grandes personajes malagueños que se vieron involucrados en hechos de la Historia de América entre los siglos XVI-XVIII.

2. C. Gómez Pérez y J. Marchena Fernández (1985), 131.

3. Id. 
colectivo de conquistadores, entre ellos los de Mario Góngora, James Lockhart, María Luisa López Spínola o María Justina Sarabia Viejo 4 .

Así que tomando como referencia estas investigaciones y mediante un laborioso análisis de las fuentes documentales conservadas en el Archivo General de Indias se ha conseguido rescatar el nombre y los hechos de algunos malagueños que se vieron inmersos en la empresa de conquista y colonización de la Florida y de los que trataremos en los siguientes apartados ${ }^{5}$.

\section{LA "TERRA FLORIDA" EN LA PRIMERA MITAD DEL SIGLO XVI}

Aunque el estudio se centra principalmente sobre la presencia malacitana en la Florida durante el intervalo temporal de 1565-1570. Es sin duda conveniente realizar una panorámica histórica de este singular territorio, el cual marcó uno de los límites norte de la expansión territorial hispana en suelo americano. De esta forma y como todo territorio del Nuevo Mundo, la Florida pasó por las sucesivas etapas de descubrimiento, conquista, colonización y evangelización que llevaron a cabo los españoles en las Indias. Sin embargo, fue siempre un territorio hostil a la presencia hispana, donde muchas empresas fracasaron ante las adversidades climáticas, la feroz resistencia indígena y las inexistentes riquezas metalíferas, cayendo esta frontera de la América hispana en el olvido. Sólo volvió a pensarse en ella a raíz de la intromisión de Francia en la región, presencia que podría acarrear problemas de índole político (enfrentamientos con Francia), económico (bases para atacar las flotas del oro y plata americanos) y religioso (hervidero de calvinistas frente al catolicismo hispano). Tan sólo un titánico esfuerzo durante el reinado de Felipe II dio resultado, y esa fue la empresa liderada por el gran marino Pedro Menéndez de Avilés, quien logró lo que ninguna otra había conseguido, el establecimiento de varios asentamientos y fuertes en la Florida.

El descubrimiento de la Florida correspondió al antiguo conquistador y gobernador de Puerto Rico Juan Ponce de León. Para llevar a cabo la empresa

4. M. Góngora (1962); J. Lockhart (1972); Ma . L. Díaz-Trechuelo LóPez Spínola (1994), 74-96 y Ma. J. SARABia Viejo (1993b), 135-146.

5. El autor del presente artículo también ha contribuido con otros trabajos a difundir la participación malagueña en la exploración y conquista de América y Oceanía: D. Cuevas GóngORA (2012), 325-334; (2013b), 271-281 y (2015), 79-104. 
era preciso firmar una capitulación entre un particular y la Corona ${ }^{6}$, Ponce de León capituló en 1512 con el rey Fernando el Católico realizar una expedición hacia la isla de Bimini, el motivo de tal viaje parecía ser la búsqueda de un lugar mítico, algo muy común en los primeros años del descubrimiento, en este caso fue la denominada "Fuente de la Eterna Juventud". No obstante la historiadora María Antonia Sáinz piensa que fue más un intento de alcanzar mayores glorias y méritos, además de desprenderse de la ociosidad y envidias que se estaban gestando en Puerto Rico. En 1513 partió Ponce de León avistando el 27 de marzo una tierra que denominó la Florida. Las alternativas para la elección de este denominativo fluctúan entre la exuberante vegetación del lugar o por ser el día en el calendario cristiano de la Pascua Florida. Ponce de León recorrió las costas este y oeste de la Florida llegando a la bahía de Tampa donde contactó con los nativos de la zona, poco después regresó a Puerto Rico y al año siguiente (1514) solicitó una nueva capitulación. Sin embargo por diversas vicisitudes de índole personal y económica la expedición se retrasó hasta 1521. En este segundo viaje el objetivo era establecer una base para explorar el territorio, pero al llegar a la bahía de Tampa fueron recibidos hostilmente por los indígenas. El resultado fueron muchos muertos y el resto gravemente heridos, entre estos últimos estaba el propio Juan Ponce de León, quien optó por retirarse a Cuba, donde fallecería a causa de las heridas recibidas ${ }^{7}$.

Pese al mal inició de la ocupación de la Florida, otro español, Lucas Vázquez de Ayllón, se interesó por el territorio descubierto por Ponce de León. En un viaje de reconocimiento envió a Francisco de Gordillo, quien llegó a una tierra llamada "Chicora" en el actual estado norteamericano de Carolina del Sur. Sin embargo Gordillo se dedicó a la captura de nativos para venderlos como esclavos en las Antillas, actividad que enfureció al propio Vázquez de Ayllón, llevándolo a organizar él mismo otra expedición para ocupar la tierra hallada por Gor-

\footnotetext{
6. Según la historiadora Milagros del Vas Mingo la capitulación consistía en un contrato o acuerdo entre dos partes. Además de otorgar un carácter jurídico a la empresa de conquista así como la entrega por parte de la Corona al particular (capitulante) una serie de concesiones de carácter político, militar y económico. M. DEL VAS MinGo (1986), 44-46.

7. $\mathbf{M}^{\mathrm{a}}$. A. SÁINZ SASTRE (2012), 51-59.
} 
dillo. Ayllón capituló su empresa con la Corona española en 1523 pero los preparativos de ésta se dilataron hasta 1526 , fecha en la que parte desde Santo Domingo. El viaje fue accidentado al perderse uno de los navíos, a ello se le sumó la hostilidad indígena, pero a pesar de todo Ayllón consiguió establecer un asentamiento hispano en la región, San Miguel de Guadalpe. Sin embargo, el hambre, la enfermedad, las malas condiciones climáticas y la belicosidad de los nativos debilitaron a los colonos, pereciendo la mayor parte de ellos y enfermando el resto, entre ellos Vázquez de Ayllón, que finalmente falleció en 1526. Su sucesor en el mando decidió desmantelar el enclave hispano y regresar a Santo Domingo, durante la travesía se arrojó al mar el cadáver de Ayllón ante el temor de que se propagase alguna epidemia ${ }^{8}$.

Otras dos expediciones dedicadas a la búsqueda de las riquezas metalíferas en la Florida y que acabaron en sendos fracasos fueron las de Pánfilo de Narváez en 1527 y la de Hernando de Soto en 1538. La primera acabó con la vida de Narváez y de sus 300 hombres, tan sólo se salvaron cuatro personas: Alvar Núñez Cabeza de Vaca, autor de una relación de lo acaecido durante el viaje ${ }^{9}$, Andrés Dorantes, Antonio del Castillo y el negro Estebanico; la expedición estuvo llena de casos de hambruna, canibalismo y enfrentamientos con los nativos ${ }^{10}$. La segunda fue liderada por el antiguo conquistador Hernando de Soto y financiada por el botín que obtuvo en Perú, no halló las riquezas esperadas y tras muchos padecimientos enfermó, muriendo al poco tiempo así como la mayoría de sus hombres. El cuerpo de Hernando de Soto fue enterrado en el río Mississippi en 1541, un año después los pocos supervivientes al mando de Luis de Moscoso y tras construir unas rudimentarias embarcaciones consiguieron llegar a las costas novohispanas ${ }^{11}$.

Ante el fracaso de la tentativa conquistadora se optó por otra vía menos intrusiva y más pacífica. Este fue el de la evangelización y siguiendo los dictámenes de las reflexiones de fray Bartolomé de las Casas en cuanto al trato

8. Ibid., 63-67.

9. A. NúÑez Cabeza De VaCa, (2001).

10. Ma . A. SÁINZ SASTRE (2012), 69-85.

11. Ibid, 87-109. 
indígena y los beneficios de la empresa espiritual frente a los métodos de la conquista.

De esta forma en 1547 el virrey de Nueva España don Antonio de Mendoza concedió licencia a la campaña evangelizadora hacia la Florida encabezada por fray Luis de Cáncer, fiel seguidor de la doctrina lascasiana, y acompañado de otros cuatro religiosos y una guía indígena llamada Magdalena. En 1549 tuvo lugar la partida de la misión evangelizadora desde el puerto de Veracruz. Sin embargo, una vez llegados a su destino, la empresa espiritual resultó otro rotundo fracaso, pues una primera avanzadilla de misioneros fue atacada por los nativos y un segundo intento realizado por el propio Cáncer acabó con la vida de éste. El resto de misioneros y los marineros de la embarcación ante la dantesca escena resolvieron regresar a Nueva España ${ }^{12}$.

La Florida seguía resistiéndose al establecimiento de la presencia hispana en sus tierras, pues hasta ahora hemos visto que tanto los métodos propios de la conquista (huestes armadas) como los acercamientos pacíficos de la evangelización cristiana habían resultado ineficaces. No obstante, la Florida continuaba constituyendo un territorio estratégico para el imperio ultramarino de España, al ser ruta obligada de las flotas del oro y plata americanos. Así, la noticia de la presencia corsaria francesa por la zona contribuyó a confeccionar un nuevo intento de ocupación de la región por parte de España.

El organizador fue nuevamente el virrey de Nueva España, quien armó una nueva expedición al mando de Tristán de Luna y Arellano, la cual salió en 1559 y compuesta de unos 1.500 efectivos humanos entre soldados y colonos. Luna estableció un asentamiento en la bahía de Mobile (Santa María de Filipina), pero su mala gestión y organización de la colonia dio al traste con la empresa, obligando con ello al virrey a destituirlo y nombrar en su lugar a Villafañe. Éste intentó fundar un enclave en Santa Elena (Carolina del Sur) sin éxito, forzándolo a evacuar a todos los hombres que quedaban en la Florida a la isla de Cuba en $1561^{13}$. 


\section{LA ARMADA DE PEDRO MENÉNDEZ DE AVILÉS}

\section{Los malagueños de Avilés}

Las noticias de la instalación de una colonia francesa ${ }^{14}$ calvinista en territorio de la Florida inquietaron a la Corona española. Por ello, el monarca Felipe II buscó poner solución a las pretensiones francesas y capituló con el avilesino don Pedro Menéndez de Avilés armar una flota y reclutar efectivos humanos para expulsar a los intrusos y proceder a la colonización española de la Florida, además de levantar una línea de fuertes con sus guarniciones para la defensa ante la piratería. Entre los soldados alistados figuraban unos 300 hombres a sueldo del rey, mientras que el resto serían recompensados con tierras y repartimientos en la región ${ }^{15}$. Ya entre ese contingente de tres centenares de hombres figuraron los primeros malagueños que partirían en la embarcación capitana de Menéndez de Avilés, el galeón San Pelayo, se trata de los antequeranos Alonso de Tejada y Juan de Valderrama, y el rondeño Cristóbal Villegas Fajardo ${ }^{16}$.

De los dos antequeranos carecemos de detalles sobre que participación tuvieron con el adelantado Menéndez de Avilés en su empresa de colonización y conquista de la Florida, ya que sus nombres no aparecen en ninguna información o crónica de la época. En cambio si contamos con las actividades del soldado Cristóbal Villegas Fajardo, gracias a la existencia de una probanza de méritos y servicios que realizó en la ciudad de México.

De los testigos de la probanza levantada por Fajardo en México el 15 de enero de $1582^{17}$, cuatro de ellos habían estado con él en la Florida, se trata de los capitanes Hernando de Múxica y Cristóbal de Herrera, el artillero y polvorista Juan Pérez Pichelero y el soldado Francisco Calderón. Según sus declaraciones, a la llegada de la armada de Pedro Menéndez de Avilés a la Florida

14. Archivo General de Indias (AGI), Patronato, 19, R.14. Declaración del parisino Stefano de Rojomonte, francés capturado y llevado a la isla de Cuba sobre la presencia francesa en la Florida (1565).

15. AGI, Indiferente, 415, L.1, ff. 45r-51v. Capitulación con Pedro Menéndez de Avilés.

16. Sus nombres y lugares de procedencia aparecen en una lista de esos 300 soldados que iban a cuenta del rey, la cual se halla entre la documentación de: AGI, Justicia, 901, N.2 (1570-1571). Añadir también que no son los únicos andaluces de esa lista pues figuran también: 30 sevillanos, 3 gaditanos, 1 almeriense, 2 onubenses, 1 cordobés, 4 jienenses y 4 granadinos.

17. AGI, México, 216, N.34. Información de méritos y servicios de Cristóbal Villegas Fajardo, México, 15 de enero de 1582. 
toparon con los navíos del francés Juan Ribault y éstos ante la presencia española decidieron huir; enviando el adelantado Avilés tras ellos un bergantín. El capitán Múxica contó que al ser de noche no vio si en esa embarcación iba Fajardo, sin embargo el testimonio del capitán Herrera (Fajardo era soldado de su compañía) afirmó que Fajardo estaba en el bergantín y tras la persecución consiguieron atrapar tres embarcaciones francesas. Posteriormente la gente traída por el Adelantado fue desembarcada en San Agustín de la Florida. Una vez erigido el asiento de la colonia hispana, Menéndez de Avilés reunió a sus hombres y marchó con ellos durante tres días por pantanos y tierras anegadizas hasta llegar a la fortificación francesa de Fort Carolina ${ }^{18}$ (los españoles lo llamarán San Mateo, día en que tomaron el fuerte), acontecimiento en el que estuvo presente según todos los testigos, el rondeño Fajardo. Ocupado el fuerte por las fuerzas españolas tras aniquilar a todos sus residentes, salvo mujeres y niños, recibió la noticia Menéndez de Avilés del naufragio de la armada de Ribault en las costas de Florida. En su búsqueda fue el Adelantado, encontrándolo según el capitán Herrera en el río que llamaban de los "Mosquitos" y que el testigo Juan Pérez Pichelero denomina de "Matanzas" (actualmente conserva este apelativo). Ribault y los franceses son degollados en la playa, presenciando la escena el propio Fajardo como soldado que acompañó a Avilés. Por último los cuatro testigos son unánimes al señalar que Cristóbal Villegas Fajardo fue a la Florida pertrechado con sus armas y un criado, por motivos de enfermedad solicitó al Adelantado licencia para retirarse, quien finalmente se la concedió, y sin haber recibido paga alguna por sus servicios. Esto último no era cierto, pues por otra documentación sabemos que Fajardo fue uno de los 300 hombres que iban en la armada con sueldo del rey ${ }^{19}$. La última noticia sobre este rondeño era la de figurar como testigo en una información de la viuda e hijos del capitán Hernando de Múxica realizada en México el 25 de marzo de 1613, donde decía tener más de setenta años ${ }^{20}$.

18. La ubicación de esta fortificación sigue siendo un misterio histórico y arqueológico, ya que aún no ha sido posible localizar el lugar exacto donde estuvo.

19. AGI, Justicia, 901, N.2 (1570-1571).

20. AGI, México, 231, N.13. Información de Catalina Agúndez mujer que fue del capitán Hernando de Múxica. México, 25 de marzo de 1613. 


\section{El capitán Diego de Luna}

Durante los preparativos de la armada de Pedro Menéndez de Avilés con destino a la Florida, el 25 de mayo de 1565 expidió en Sevilla el nombramiento de capitán a Diego de Luna, natural de la ciudad de Málaga, el documento en cuestión le facultaba para levantar una compañía de 100 hombres de infantería por cuya participación recibirían tierras y repartimientos en la Flori$\mathrm{da}^{21}$. La reconstrucción de lo acaecido al capitán Luna y su compañía se entresaca del pleito que mantuvo Luna con el propio adelantado Pedro Menéndez de Avilés en cuanto a los gastos y servicios del malagueño ${ }^{22}$.

Una vez concedida la conducta que le otorgaba el cargo de capitán, Diego de Luna se dirigió a la ciudad de Málaga, donde reclutó a los hombres, uno de ellos fue el malacitano Hernando de Aseso quien dijo: "vido como por virtud de la conduta que su magestad le dio al dicho capitán hizo en Málaga toda la gente". Reunida la soldadesca, el capitán Luna marchó con ellos a Cádiz, a su llegada supo de la partida del adelantado Avilés hacia la Florida el día anterior. La noticia produjo las primeras bajas en la tropa, pues algunos decidieron volver a Málaga, entre ellos Hernando de Aseso $^{23}$, quedándole según el testigo Alonso de Orozco: "ochenta y uno o ochenta y dos". Poco después, Luna buscó en la ciudad gaditana al factor de la Casa de la Contratación, Francisco Duarte, para que le ayudase a reunirse con Avilés, sin embargo éste lo remitió directamente al apoderado de Avilés, el regidor Pedro del Castillo, quien finalmente gestionó el embarque de la gente de Luna en una carabela con destino a las Canarias, pues hacia allí iba Avilés, y en caso de no encontrarlo, debería esperar a la armada creada en Asturias con destino a la Florida. Durante la estancia de la compañía de Luna en Cádiz algunos testigos evidenciaron el

21. Este nombramiento de capitán para el malagueño Diego de Luna se encuentra entre la documentación del pleito que mantuvo este último con el adelantado Avilés por su participación en la jornada de la Florida. AGI, Justicia, 879, N.3. Contiene varias probanzas y documentos de los años de 1566-1568.

22. AGI, Justicia, 879, N.3.

23. Declaración de Hernando de Aseso en la probanza presentada por el capitán Luna ante la Casa de la Contratación realizada en Sevilla, el 17 de Octubre de 1566. Esta se incluye entre los papeles de AGI, Justicia, 879, N.3. 
estado de desamparo de los hombres por falta de víveres, situación que quiso remediar Luna vendiendo si hiciese falta una cadena de oro de su propiedad ${ }^{24}$. En Canarias reciben la noticia de la salida de Avilés, por tanto, y siguiendo las instrucciones de Castillo, esperaron la llegada de la armada de Asturias. Fueron más de 20 días, intervalo de tiempo que aprovechó Luna para reclutar nuevos soldados. Además se volvieron a evidenciar problemas de abastecimiento de la hueste; remediados en parte por el cabildo canario ${ }^{25}$.

Arribada la armada de Asturias al mando de Esteban de las Alas y Pedro Menéndez Márquez, la compañía de Diego de Luna fue repartida en tres de los cinco navíos ${ }^{26}$. Parten desde las Canarias tocando diversas islas de las Antillas. Así, a la altura de la isla Dominica tuvieron un encuentro con un barco francés, donde al parecer se mostró la incapacidad de Luna y sus hombres ${ }^{27}$. Poco después toman puerto en Guadinilla (Puerto Rico), aquí desembarcaron todos los soldados para refrescarse, oportunidad que aprovecharon varios para desertar y esconderse en la isla. Entonces se encomendó al malagueño Diego de Luna junto con algunos hombres de su capitanía la búsqueda de los huidos, pues al parecer la mayoría de los fugitivos pertenecían a su compañía ${ }^{28}$. Tras hacer las pesquisas pertinentes no se pudo reunir a todos los evadidos.

24. Así lo declararon Pedro de Zubiurite: "y estando unas moças a la puerta cargadas con unas çestas en que llevaban pan a vender, vio este testigo que algunos delos dichos soldados dezían al cabo de esquadra que les prestase dineros para comprar de aquel pan y el dicho cabo de esquadra respondió que no tenía dineros, que luego vernía el capitán y lo provehería" (f.5v) y Alonso de Orozco: "vio este testigo que el sargento dixo al dicho Diego de Luna que mandase proveer de comer a los soldados que estaban desabridos, y el dicho Diego de Luna dixo delante del dicho Francisco Duarte (...) que solo esta cadena de oro me a quedado y esta venderé para que coman" (f. 7v). Declaraciones contenidas en la Probanza del capitán Diego de Luna en el pleito con el adelantado Pedro Menéndez, incluida en: AGI, Justicia, 879, N.3.

25. Testimonios del oidor de Gran Canaria, Andrés de Espinosa (ff. 5v-6r) y Juan de Villalta, deán de Canarias, éste último incluso dijo: "no permitiesen que los soldados de su magestad muriesen de hambre en tierra de cristianos" (ff. 6r-6v). Probanza del capitán Diego de Luna en el pleito con el adelantado Pedro Menéndez: AGI, Justicia, 879, N.3.

26. En una información hecha en la Habana por el capitán Diego de Luna el 22 de junio de 1566. Contenida entre los papeles de $A G I$, Justicia, 879, N.3. El testigo Pedro de Castañeda respondió que en el barco de Esteban de las Alas iban 20 soldados, en el de Pedro de Ejalde unos 25 ó 30 con el alférez y en la carabela de Menéndez Márquez iba Diego de Luna, suponemos que con el resto.

27. Declaración de Diego de Miranda (Quirós, Asturias), integrante de la armada de Asturias, en la Probanza del adelantado Pedro Menéndez de Avilés en el pleito con el capitán Diego de Luna. AGI, Justicia, 879, N.3, ff. 12v-14r.

28. Así lo afirmaron los asturianos Juan de Valdés, Diego de Miranda y Álvaro de Valdés como testigos en la Probanza del adelantado Pedro Menéndez de Avilés en el pleito con el capitán Diego de Luna. AGI, Justicia, 879, N.3, ff. 8v-10r, 12v-14r y 14v-16r. También lo cuenta el mismo Diego de Miranda en la Probanza del capitán Diego de Luna en el pleito con el adelantado Pedro Menéndez: AGI, Justicia, 879, N.3, ff. 12r-13r. 
Reembarcados de nuevo en la armada prosiguen su viaje, y en cierto punto de la geografía caribeña avistan dos barcos de nacionalidad portuguesa que andaban de contrabando por la zona, los cuales se rinden ante la presencia hispana. En esta acción, Diego de Luna reclamó al capitán de las Alas y al almirante Menéndez Márquez que distribuyesen el botín también entre sus hombres como partícipes de la rendición de las carabelas portuguesas, pero los asturianos no estuvieron del todo de acuerdo, ya que ninguno de sus soldados fue útil, afirmación que contó con el testimonio de varios integrantes de la armada asturiana ${ }^{29}$. Tras la captura de los navíos lusos la armada prosigue la navegación arribando al puerto cubano de Matanzas, y de ahí a la Habana, enclave donde desertarían más hombres de Luna, restándole a la llegada del adelantado Avilés al lugar, unos 20 ó 30, la gran mayoría no aptos para el servicio militar, a excepción del alférez Diego de Ojeda ${ }^{30}$.

Reunidos Diego de Luna y el adelantado Pedro Menéndez de Avilés en la Habana, éste último le comisionó para llevar ciertas cartas a la Real Audiencia de México con el fin de comunicarles la victoria obtenida sobre los franceses en la Florida y el envío de ayuda para los soldados. Luna realizó este cometido y volvió a la Habana, aquí solicitó al adelantado licencia para regresar a España por problemas de salud ${ }^{31}$. Sin embargo existe otra versión sobre estos hechos, parece ser que cuando Avilés entregó a Luna las cartas, le llegó a sus oídos el rumor de la pretensión de Luna y algunos de sus soldados de quedarse en Nueva España. Entonces el Adelantado optó por quitarle las cartas a Luna

29. Se trata de Juan de Valdés, Diego de Miranda y Diego Menéndez. Probanza del adelantado Pedro Menéndez de Avilés en el pleito con el capitán Diego de Luna. AGI, Justicia, 879 , N.3, ff. $8 \mathrm{v}-10 \mathrm{r}, 12 \mathrm{v}-14 \mathrm{r}$ y $20 \mathrm{v}-21 \mathrm{v}$.

30. Sobre el viaje de Matanzas a la Habana, lo señalan los testigos Diego de Miranda (miembro de la armada de Asturias) y el gobernador de Cuba en ese momento Diego de Mazariegos en la Probanza del capitán Diego de Luna en el pleito con el adelantado Pedro Menéndez: AGI, Justicia, 879, N.3, ff. 12r-13r y 13v. En cuanto al número de soldados de Luna a la llegada de Avilés contamos con las declaraciones de varios testigos de la Probanza del adelantado Pedro Menéndez de Avilés en el pleito con el capitán Diego de Luna. AGI, Justicia, 879, N.3, ff. 8v-10r (Juan Valdés), ff. 10v-11v (Francisco Cepero), ff. 14v-16r (Álvaro de Valdés), ff. 17r-18r (Francisco del Rosal), ff. 18r-20r (bachiller Andrés de Valdés), ff. 22r-23r (Francisco Núñez de Castañeda), ff. 23v-24v (Alonso Núñez) y ff. $25 \mathrm{r}-27 \mathrm{v}$ (Gonzalo de Solís).

31. Así lo relataron algunos testigos comparecientes en la Probanza del capitán Diego de Luna en el pleito con el adelantado Pedro Menéndez: AGI, Justicia, 879, N.3. El licenciado Carvajal, lo vio en Nueva España y le acompañó hasta la Habana (ff. 8r-8v), el oidor de Guatemala, García Jofre de Loaysa observó en el aposento del licenciado Valderrama a Luna y los despachos y advirtió: "como enviaba al dicho capitán Luna y a otro fulano de Solís", asimismo señaló: "le avía pedido liçençia para se venir a España porque se sentía mal dispuesto" (ff. 9r-9v), el contador de Cuba Diego López Durán también confirmó la historia (ff. 9v-10r), así como Andrés Maldonado (ff.11r-11v). 
y entregárselas a Gonzalo Solís de Merás (cuñado de Avilés). No obstante, esto no fue impedimento alguno para que Luna y parte de sus hombres aprovechasen una noche para subir secretamente a un navío que hacía la ruta hacia México. El Adelantado enterado del suceso, ordenó a Solís que se dirigiese a Campeche y México en busca y captura de Luna y sus acompañantes para traerlos ante su presencia. Gonzalo Solís localizó a Luna en Campeche, pero señala el propio Solís en su declaración que al carecer de medios para apresarlo, usó cierta artimaña, consistente en la entrega a Diego de Luna de uno de los duplicados de los despachos para la Audiencia de México, bajo la premisa de que irían juntos a llevárselos. La estratagema no resultó del todo ya que Luna se adelantó y llegó antes que Solís a México, posteriormente reembarcarían con la flota de Nueva España que hacía escala en la Habana, donde suplicó al Adelantado licencia para su regreso a la Península ${ }^{32}$.

Sólo nos resta saber que pasó con los escasos hombres que aportó el capitán malagueño Diego de Luna, pues bien, éstos fueron enviados junto con el alférez Diego de Ojeda a la Florida y la mayor parte de ellos se vieron involucrados en motines y abandonaron la Florida, entre los acusados estaban Pedro de Castañeda, Cristóbal Garrido y Luis Pardillo ${ }^{33}$, éstos dos últimos reclutados en Canarias; otros testigos señalan también a un cerrajero y a un tal Carballo.

Así, el piloto Gregorio gallego respondió a la pregunta 20 de la probanza del adelantado Avilés lo siguiente:

Se huyeron de la Florida çiertos soldados de los que llevó el dicho Diego de Luna de los quales quando volvió este testigo de la Florida, viniendo por la isla de Cuba a la Habana en hatos de ganados topó algunos de los que se huyeron y entre ellos conoçió dos o tres de la compañía del dicho Diego de Luna, aunque por nombre no save como se llamaban y el uno de ellos hera çerrajero ${ }^{34}$.

32. La otra versión procede de los testimonios de los testigos Juan de Valdés, Francisco Cepero, Álvaro Valdés, bachiller Andrés de Valdés y tal vez el más importante de todos, el del propio Gonzalo de Solís. Probanza del adelantado Pedro Menéndez de Avilés en el pleito con el capitán Diego de Luna. AGI, Justicia, 879, N.3, ff. 8v-10r, 10v-11v, 14v-16r, $18 \mathrm{r}-20 \mathrm{r}$ y $25 \mathrm{r}-27 \mathrm{v}$.

33. Curiosamente estos tres amotinados comparecieron como testigos en una información realizada por Diego de Luna en la Habana en Junio de 1566 y contenida en AGI, Justicia, 879 , N.3.

34. Declaración de Gregorio gallego en la Probanza del adelantado Pedro Menéndez de Avilés en el pleito con el capitán Diego de Luna. AGI, Justicia, 879, N.3, f. 8r. 
El miembro de la armada de Asturias, el soldado Juan de Valdés relató lo siguiente:

Este testigo save que çiertos solados que fueron diez o doze de ellos que fueron con el dicho Diego de Luna se amotinaron en el fuerte de Santa Helena ${ }^{35}$ en la Florida y se huyeron y ausentaron pero que este testigo no tiene memoria de sus nombres más de solamente el uno dellos que se acuerda que se llamaba Carva$10^{36}$.

Asimismo, el testigo, también integrante de la armada de Asturias, Diego de Miranda (Quirós, Asturias), conoció la huida de Garrido de la Florida, porque lo encontró más tarde en Cuba y que Pardillo se había marchado a México $^{37}$. Otro testimonio referente al episodio de los soldados amotinados es el de Alonso Núñez, soldado de Cantillana que había ido a la Florida con el adelantado:

conoció a los tres soldados que la pregunta dize (se refiere a Castañeda, Garrido y Pardillo) y save este testigo que fueron de los del dicho Diego de Luna y con aver ido a la florida después de aver hecho el hefecto se amotinaron e huyeron y lo save porque lo vio y se halló presente ${ }^{38}$.

Como final del intrincado asunto de Luna y su compañía de soldados hemos dejado el propio testimonio del adelantado Pedro Menéndez de Avilés, quien fue presentado por testigo en la propia probanza de Diego de Luna realizada en Madrid en 1567. El Adelantado negó muchos de los contenidos de las preguntas formuladas. De esta manera en el asunto de las carabelas portuguesas señaló que no le correspondía botín alguno sino a él, pues los navíos que rindieron a los contrabandistas eran de su propiedad. Cuando llegó a la Habana encontró a muy pocos soldados, la mayoría desamparados y quejándosele de los agravios que les había provocado el propio Luna. Asimismo el Adelantado explica que Luna le insistió numerosas veces para que le dejase

35. El fuerte de Santa Helena ha sido hallado en la isla de Parris en el actual estado norteamericano de Carolina del Sur, este fuerte estuvo durante un tiempo a cargo del capitán Esteban de las Alas.

36. Respuesta de Juan Valdés a la pregunta 20 de la Probanza del adelantado Pedro Menéndez de Avilés en el pleito con el capitán Diego de Luna. AGI, Justicia, 879, N.3, f. 10r.

37. Probanza del adelantado Pedro Menéndez de Avilés en el pleito con el capitán Diego de Luna. AGI, Justicia, 879, N.3, f. 14r.

38. AGI, Justicia, 879, N.3, f. 24v. Respuesta de Alonso Núñez a la pregunta 20. 
ir a Nueva España a curarse, tras dársela y ser posteriormente informado de la pretensión de Luna de quedarse allí le sustrajo los despachos que debía llevar, y que aprovechando la noche se embarcó a México, entonces entregó a Gonzalo Solís las cartas, además de un poder para traer presos a Luna y sus acompañantes. Una vez en la Habana y por el ruego del licenciado Valderrama le concedió a Luna el pasaje para regresar a España por motivos de enfermedad, aunque el Adelantado creía que esto era una falacia, por último conoció el suceso de los motines de los hombres de Luna ${ }^{39}$.

La última cuestión que nos falta es ¿quién ganó el pleito?, la respuesta proviene de una carta del propio Consejo de Indias fechada en Madrid el 27 de enero de 1568, donde se señala que el capitán Diego de Luna probó sus argumentos y manda al adelantado Avilés que le pague 50.000 maravedís, quedando absueltos ambos de las acusaciones y demás demandas interpuestas en los respectivos pleitos ${ }^{40}$.

\section{Un viaje hacia el Norte}

Una expedición bastante curiosa fue la enviada desde el fuerte de San Mateo en agosto de 1566 por el adelantado Menéndez de Avilés para establecer un puesto avanzado en la tierra del indio don Luis, la cual se ubicada entre los $36^{\circ}$ y $39^{\circ}$ Norte (y que comprendería los actuales estados de Carolina del Norte y Virginia). Para ello nombró como capitán al asturiano Pedro de Coronas, alférez de la compañía de Rodrigo Troche y participante en la toma del fuerte francés, a quien acompañarían una veintena de soldados y dos frailes (fray Pablo de San Pedro, de Jerez de la Frontera y fray Juan de Acuña, de Granada) con la misión de establecer un puesto avanzado. Entre la lista de los 20 soldados que embarcarían en el navío Trinidad, figura entre otros andaluces, el vecino de Ronda Antonio Morales de Carrasquilla, hijo de Juan Ruiz de Carrasquilla y María Díaz ${ }^{41}$.

Tras partir desde el fuerte de San Mateo llegan el 14 de agosto de 1566 a un río ubicado a $37^{\circ}$ y medio de latitud Norte según las mediciones del piloto

39. Declaración del adelantado Pedro Menéndez de Avilés en la Probanza del capitán Diego de Luna en el pleito con el adelantado Pedro Menéndez: AGI, Justicia, 879, N.3, ff. $14 \mathrm{r}-16 \mathrm{r}$.

40. La carta se encuentra entre los papeles de AGI, Justicia, 879, N.3.

41. La lista de los hombres que van en la expedición se localiza en AGI, Patronato, 257, N.1, G.3, R.4, ff. 3r-4r. 
de la Trinidad Domingo Hernández. Diez día después y tras un temporal, el navío encuentra otro río a $36^{\circ}$, donde desembarcaron varios hombres ${ }^{42}$. Una vez en tierra, Coronas solicitó al escribano Diego de Camargo recogiese testimonio de la toma de posesión de la tierra: "el dicho capitán Pedro de Coronas se paseó por la dicha tierra y cortó rramas de un árbol y hizo una cruz y la hincó en la playa en la dicha tierra", posteriormente al río lo bautizaron como de San Bartolomé por llegar el día 25 de agosto al lugar. Explorado el río y sin contacto con los habitantes de la zona, la hueste regresa al punto de partida. Reunidos todos se decidió abandonar el río de San Bartolomé y navegar nuevamente a la posición de $\operatorname{los} 37^{\circ}$ y medio, lugar donde vieron un río la primera vez que llegaron ${ }^{43}$.

Navegando en dirección a los $37^{\circ}$ y medio parece ser que sobrevino un fuerte viento que obligó al piloto Hernández a dar la vuelta en dirección al mar, la tormenta duró unos 3 días. El 3 de septiembre de 1566 regresaron a la entrada del río, pero un nuevo temporal les impide tomar tierra. Los constantes impedimentos climáticos llevan a Coronas a reunir al escribano y al piloto, se llegó a dos alternativas ante la imposibilidad del desembarco: una era volver a San Mateo, la otra dirigirse a cualquier parte donde pudiesen servir al rey. Así pues, comunican al piloto cual era su elección de las tres opciones que se barajaban: San Mateo, Islas de Barlovento (Santo Domingo o Puerto Rico) o España. El piloto respondió que la $1^{a}$ opción era inviable por ser tiempo de huracanes, la $2^{\mathrm{a}}$ también por malos tiempos y que la $3^{\mathrm{a}}$ era la más acertada por ser las condiciones metereológicas óptimas para la navegación hacia España ${ }^{44}$.

Ante esta determinación se optó por reunir al "cabildo", compuesto por los oficiales y soldados para que en votación eligiesen la opción que deberían tomar. De los 18 votantes: 12 votaron por ir a España, 5 por dirigirse a las islas de Barlovento y 1 al hallarse enfermo dijo que su voto fuese para la decisión de la mayoría. El rondeño Antonio Morales de Carrasquilla fue de la parcialidad de los que querían volver a España ${ }^{45}$. Por tanto, la opción de regresar a la Península fue la elegida, llegando a Cádiz en octubre de 1566.

42. AGI, Patronato, 257, N.1, G.3, R.4, ff. 8r-9r.

43. AGI, Patronato, 257, N.1, G.3, R.4, ff. 9r-10v.

44. AGI, Patronato, 257, N.1, G.3, R.4, ff. 11r-12v.

45. AGI, Patronato, 257, N.1, G.3, R.4, ff. 13r-16v. 


\section{Refuerzos para la Florida: la Armada de Sancho de Archiniega}

El aviso de la creación de nuevas armadas en Francia e Inglaterra con destino a la Florida llevó al monarca Felipe II a equipar una armada de apoyo para Menéndez de Avilés, reclutándose para tal efecto unos 1.500 soldados que irían al mando del general Sancho de Archiniega. El alistamiento de los efectivos militares se realizó en diversas regiones de Andalucía, concretamente el capitán Pedro de Redrován reclutaría 250 hombres en Málaga, otros 250 en Úbeda y Baeza el capitán Pedro de Andrada, la misma cantidad haría el capitán Juan Pardo en Córdoba, y también el capitán Juan de Zurita en Jerez de la Frontera, y por último otros 250 hombres en Sevilla por el maese de campo de la armada ${ }^{46}$.

De los supuestos 250 malagueños que el capitán Pedro de Redrován tenía que juntar para su posterior reparto entre las diversas compañías, he conseguido reunir el nombre de diez de ellos ${ }^{47}$ : seis eran de la propia ciudad de Málaga (Bartolomé Moreno, Cristóbal de Berrio, Andrés de Vera, Pedro de Cahices, Pedro Hernández de Málaga y Bernaldino García), uno de Ronda (Domingo Hernández), uno de Ortejícar (Juan Hernández) y dos de Vélez-Málaga (Baltasar Romero y Antonio de la Quadra).

Bartolomé Moreno ${ }^{48}$ por su declaración realizada en Sevilla en el asunto del sueldo de Hernando Mulero (participante en armada de Archiniega) decía ser "natural de la çiudad de Málaga, vecino desta çiudad (Sevilla) en la colación de Santa María (...) soldado que sirvió a su magestad en las provincias de la Florida" ${ }^{49}$. Asimismo dijo conocer a Mulero desde su salida de Cádiz en la armada de Archiniega con destino a la Florida en 1566 y que una vez llegados allí, Moreno vio nombrar a Mulero como cabo de escuadra de la compañía de Juan Pardo tras la muerte de Miguel de Haro. Posteriormente también presenció su nombramiento como sargento de la compañía del coronel Oruña, la cual

46. AGI, Patronato, 19, R. 18. Diversos documentos sobre la Florida.

47. La escasez de nombres es debida a que el legajo que contiene los asientos de los soldados de la Armada de Sancho de Archiniega está en mal estado por un incendio que sufrió el Archivo General de Indias a principios del siglo XX. La localización de los nombres procede de otra documentación.

48. En la información de lo que gastó Esteban de las Alas en la gente que estaba bajo su mando declaró que era soldado de la compañía de Pedro de Redrovan y que había llegado a la Florida en la armada de Sancho de Archiniega. AGI, Justicia, 1001, N.2. R.1.

49. Declaración de Bartolomé Mulero en el pleito sobre la cobranza del sueldo del soldado Hernando Mulero, ya difunto, por el padre de éste, Gonzalo Mulero. AGI, Justicia, 933, N.5, ff. $16 \mathrm{r}-18 \mathrm{v}$. 
estaba a cargo del capitán Juan de Vasozabal, y así lo afirmaba el malagueño: "porque se halló siempre con el dicho Hernando Mulero" 50 . Otro soldado de la compañía de Redrován fue el vecino de Málaga, Pedro de Cahices, quien había residido en el fuerte de San Agustín de la Florida ${ }^{51}$.

Por otro lado, una de las compañías embarcadas en la armada de Archiniega, la del coronel Oruña, donde figuraban los malagueños Andrés de Vera y Cristóbal de Berrio $^{52}$, carecía de oficiales pues Vera decía: "el Coronel Hernando de Oruña e se quedo él y los dichos oficiales en España". Por ello era necesario el nombramiento de nuevos oficiales que dirigiesen la hueste de soldados. Fue Juan de Aguirre Garibay, integrante de la compañía del capitán Zurita, quien obtuvo el cargo de alférez de la compañía de Oruña para una vez en San Agustín, ser ascendido a capitán. Luego recibió la orden de marchar con sus soldados al fuerte de San Mateo para ayudar a su reforzamiento. Desde aquí y tomando como información lo contenido en la pregunta 13 el capitán Aguirre Garibay formó parte de una expedición para explorar el río de San Mateo (actual Saint John's river), bergantín en el que también iba el malagueño Cristóbal de Berrio, y que a la vuelta sufrió el naufragio de la embarcación, así lo cuenta Berrio:

Que este testigo yba en el mesmo bergantín que la pregunta dize, donde asimismo yba el capitán Aguirre en compañía de otros capitanes y soldados que de ende yban para descubrir el Río de San Mateo y bolviendo el dicho descubrimiento, el dicho bergantín dio al través con temporal y todos los capitanes y soldados salieron a nado e perdieron las ropas y armas que llevaban y asimismo entre ellos el dicho capitán perdió las suyas y él y este testigo salieron a nado... ${ }^{53}$

Poco después la compañía del capitán Aguirre Garibay regresó a San Mateo, donde por orden del adelantado Menéndez de Avilés embarcó con un destacamento de 50 soldados integrado por hombres de las diversas compañías traídas por el general Sancho de Archiniega, su destino era el lugar de Puerto Plata en la isla de Santo Domingo, con la tarea de servir de guarnición de la

50. Id.

51. Así lo declaró en la información de los gastos que hizo Esteban de las Alas en la Florida. AGI, Justicia, 1001, N.2. R.1.

52. Declaraciones de Andrés de Vera y Cristóbal de Berrio en la probanza de los servicios del capitán Juan de Aguirre Garibay en la Florida. Sevilla, 10 de Octubre de 1569. AGI, Justicia, 900, N.5.

53. Testimonio del malagueño Cristóbal de Berrio en la probanza del capitán Juan de Aguirre Garibay realizada en Sevilla el 10 de Octubre de 1569. Contenida entre los papeles de AGI, Justicia, 900, N.5. 
zona ante posibles ataques corsarios. Conocemos la nómina de esos soldados gracias a un alarde que el propio Garibay realizó en Puerto Plata el 19 de noviembre de 1568 , donde se señalaban los progenitores, origen geográfico y compañía a la que pertenecían. Lista en la que figuraron los siguientes malagueños.

Uno es el ya citado Andrés de Vera, aunque la lista amplía su información, así era vecino de Málaga, e hijo de Cristóbal de Vera, pasó a la Florida como soldado de la compañía del coronel Oruña por coselete (piquero), sirviendo como tal hasta el 1 de julio de 1566, data en la que fue nombrado alférez de la compañía de Aguirre Garibay, cargo que ejerció hasta el 17 de agosto de 1566, para volver a ocupar el puesto desde enero de 1567 hasta noviembre del año siguiente en la guarnición de Puerto Plata. El otro malagueño es Juan Hernández, "vezino de Hortexicar", es decir, del lugar de Ortejícar, donadío de la provincia de Málaga próximo a Ronda. Sus padres eran Juan Hernández y María Andrés y se alistó como arcabucero en la compañía de Juan Zurita para la Florida en la armada de Archiniega, en Sanlúcar recibió el equipamiento siguiente: arcabuz, 20 libras de pólvora, 20 de plomo y 20 de cuerda, así como ocho ducados de paga. Sirvió de arcabucero en la Florida hasta enero de 1567 en que embarcó como uno de los 50 soldados del capitán Garibay para la guarnición de Puerto Plata hasta ser despedido el 19 de noviembre de $1568^{54}$.

Por otro lado, doña María de Valdés, viuda del capitán Esteban de las Alas, pedía en una información el cobro de la ayuda que su marido efectuó sobre diversos soldados que se hallaron en la Florida, auto realizado en la Casa de la Contratación de Sevilla el 18 de enero de $1578^{55}$. Entre la lista de los soldados que debían dinero a los herederos de Esteban de las Alas se encontraban los siguientes malagueños ${ }^{56}$ :

- Bernaldino García (Málaga) debía entregar 10 reales de su sueldo.

- Domingo Hernández (Ronda) 88 reales.

- Antonio de la Quadra (Vélez-Málaga) 22 reales.

- Baltasar Romero (¿Vélez-Málaga?), en el documento figura como vecino de Vélez, 10 reales de su sueldo.

54. Alarde de los soldados que sirvieron con Garibay en Puerto Plata, realizada el 19 de Noviembre de 1568 y contenida entre los documentos de AGI, Justicia, 900, N.5.

55. Los herederos del general Esteban de las Alas sobre el cobró de débitos. AGI, Patronato, 254, N.1, G.2, R.4, ff. 4r-4v.

56. AGI, Patronato, 254, N.1, G.2, R.4, ff. 6v. (Bernaldino García), 7r (Domingo Hernández), 6r (Antonio de la Quadra) y 6v (Baltasar Romero). 
Otro hecho ocurrido durante el dominio hispano de la Florida fue el abandono del fuerte de San Mateo por la guarnición española en 1568 tras el ataque conjunto de franceses e indígenas. Conocemos los detalles del suceso por fuentes españolas y francesas: una es la carta de Esteban de las Alas ${ }^{57}$ (teniente de gobernador de la Florida y residente en San Agustín) y la otra se trata de una crónica ${ }^{58}$ del viaje del capitán francés Dominique Gourgue, autor del ataque en señal de venganza por lo perpetrado por los españoles tres años antes en el mismo fuerte a sus compatriotas franceses. Parece ser que entre la guarnición que residía en San Mateo al momento de su abandono se encontraba Pedro Hernández de Málaga, quién junto con otros soldados reclamaban sus sueldos del tiempo que sirvieron en la Florida ${ }^{59}$.

\section{CONCLUSIÓN}

Pedro Menéndez de Avilés para llevar con éxito la empresa que se le había ordenado; introdujo junto con los dos métodos tradicionales empleados en las Indias (huestes armadas y evangelización) el sistema de presidios y guarniciones, así como la creación de una armada que vigilase y reconociese las aguas y costas caribeñas en busca de corsarios y piratas. La elección del sistema de presidios, no era nueva, había sido un medio más o menos efectivo en la costa andaluza y norteafricana, donde había presidios con sus correspondientes guarniciones, a sueldo de la Corona, para la defensa frente la piratería berberisca y la amenaza del turco.

Prueba de ello fue la fundación de dos enclaves principales, San Agustín y Santa Elena con sus respectivos fuertes. Aparte de la construcción de un sistema de fortificaciones a lo largo de las costas de la Florida, todas ellas con un contingente militar, sin embargo la falta de recursos para mantenerlos (alimentos, ropa, armas, pagas), la constante hostilidad indígena y la preca-

57. Carta de Esteban de las Alas sobre la pérdida del fuerte de San Mateo. AGI, Patronato, 254, N.1, G.2, R.1. San Agustín de la Florida, 5 de mayo de 1568. Por otro lado, se llevó a cabo una información contra ciertos oficiales que estuvieron en el fuerte de San Mateo cuando lo desampararon: AGI, Justicia, 1000, R.5.

58. La reprise de la floride par le cappitaine Gourgue. El relato está en la Biblioteca Nacional de Francia en su sección de Manuscritos y puede consultarse en Internet: http://gallica. bnf.fr/ark:/12148/btv1b9060528r (consultado el 3 de diciembre de 2014).

59. Juan Muñoz y otros soldados sobre el cobro de sus sueldos del tiempo que sirvieron en la provincia de la Florida. AGI, Justicia, 1001, N.2, R.5. 
riedad llevaron en muchas ocasiones a la deserción de los soldados, motines y abandonos. Para la tropa los motivos más comunes fueron el escaso salario y el retraso en su cobro, siendo los solteros más proclives a abandonar sus puestos en busca de otros lugares u oficios más beneficiosos. En cambio los casados complementaban su actividad militar con otras actividades para poder así mantener a la familia ${ }^{60}$.

Esto dio lugar al desmantelamiento de la mayoría de ellos, reduciéndose a los fuertes de San Agustín, Santa Elena, San Pedro y San Mateo. Y pasado los años tan solo San Agustín quedó como único asentamiento hispano estable en la Florida, y ello se debió en palabras de Gaspar Pérez Turrado: "la incompleta financiación de las Armadas de Indias fue una constante a lo largo de su azarosa existencia" $"$.

En este contexto tan fluctuante, precario y de esfuerzo para mantener una posición estratégica en la Florida se vieron involucrados los 16 malagueños insertados en este estudio ${ }^{62}$. Algunos participaron en deserciones y motines como los de la compañía de Diego de Luna, otros reclamaron sus sueldos pasados y en menor medida cumplieron su función militar prestando servicio en las guarniciones. Rescatando a estos individuos, anónimos para la gran mayoría no solo a nivel local de la Historia de Málaga, sino también de la investigación general, mediante la prosopografía con la finalidad de integrarlos en un espacio, tiempo y mentalidad. Pues como señalamos en la introducción, se trata de una tarea difícil pero necesaria para tener un mayor conocimiento de la emigración a las Indias, de los colectivos humanos, de sus inquietudes y deseos en una etapa tan dinámica como la época del descubrimiento, conquista, colonización y evangelización de un continente nuevo, una nueva frontera. Esto ayudará a tender nuevas líneas de investigación y trabajos aunando diversos esfuerzos para seguir desentrañando la historia menos conocida.

Por último, decir que no creo que los malagueños aquí tratados sean los únicos ni los últimos, pues todavía quedan documentos por analizar, esto es tan solo, si me permiten, una primera aproximación. Por otro lado, no acaba aquí la investigación pues está en ciernes el desarrollo de un trabajo que recopile no solo a todos los malagueños que estuvieron en la Florida de 1565 a

60. G. Pérez Turrado (1992), 166.

61. Ibid., 183 .

62. Si contabilizamos como de origen malacitano a Pedro de Castañeda y el alférez Diego de Ojeda, por ser integrantes de la compañía del capitán malagueño Diego de Luna desde su salida de Cádiz. 
1600, sino en definitiva a todos los andaluces partícipes, línea de investigación en la que ya he conseguido reunir la información de más de 230 individuos. 


\section{BIBLIOGRAFÍA}

Anguita Galán, Enrique y Moreno Gómez, Jesús (1992), Malagueños en América: del orto al ocaso, Servicio de Publicaciones, Diputación Provincial, Málaga.

Cuevas GóngORA, David (2012), “Alonso Pérez Roldán: un piloto de Málaga en el segundo viaje de Cristóbal Colón”, Baetica, 34, pp. 325-334.

- (2013b), "El testamento de un conquistador del Perú: Ginés de Carranza", Baetica, 35, pp.271-281.

(2015), "Los hombres del Océano: malagueños en la Mar del Sur (15191583)" en Salvador Bernabéu Albert, Carmen Mena García y Emilio José LuQue Azcona, Conocer el Pacifico: exploraciones, imágenes y formación de sociedades oceánicas, Universidad, Sevilla, pp. 79-104.

Díaz-Trechuelo LóPez Spínola, María Lourdes (1994), "Contribución granadina a la conquista y colonización de América", en El Reino de Granada y el Nuevo Mundo, vol. I, Diputación Provincial, Granada, pp. 74-96

Gómez Pérez, Carmen y Marchena Fernández, Juan (1985), "Los señores de la guerra en la conquista de América", Anuario de Estudios Americanos, vol. XLII, pp. 127-215.

Góngora, Mario (1962), Los grupos de conquistadores en Tierra Firme (1509-1530), Universidad, Santiago de Chile.

LoCKHART, James (1972), Los de Cajamarca: un estudio social y biográfico de los primeros conquistadores del Perú, 2 vols., Milla Batres, Lima.

NúÑEz Cabeza De VaCa, Alvar (2001), Naufragios, edición de Trinidad Barrera, Alianza Editorial, Madrid.

PÉREz DE Colosía, María Isabel (1999), "El conquistador-colonizador en Indias, el caso de Gonzalo Suárez Rendón", en Actas del V Congreso Internacional de Hispanistas, Algazara, Málaga-Granada, pp. 7-22.

Pérez Turrado, Gaspar (1992), Armadas españolas de Indias, Colecciones Mapfre, Madrid.

Sáinz SASTRE, María Antonia (2012), La Florida en el siglo XVI. Exploración y colonización, Fundación Mapfre, Madrid.

Santos Arrebola, María Soledad (1999), "Las empresas de Ruy López de Villalobos por el Pacífico", en Actas del V Congreso Internacional de Hispanistas, Algazara, Málaga-Granada, pp. 23-30. 
Sarabia Viejo, María Justina (1993b), "Presencia gaditana en la conquista de México y América Central", en El Puerto, su entorno y América, Ayuntamiento, El Puerto de Santa María, pp. 135-146.

Del Vas Mingo, Milagros (1986), Las capitulaciones indianas en el siglo XVI, Instituto de Cooperación Iberoamericana, Madrid. 